\title{
An Analysis on the Turnover of College Teachers in China from the Perspective of Institutional Economics
}

\author{
Zhaojun Zhang \\ School of Economics \\ Wuhan University of Technology 430070, China \\ School of international business \\ Inner Mongolia University of Technology 010051, China \\ E-mail: zzjnmgcn@sohu.com
}

Funded project: The research is supported by the Foundation of the Eleventh Five-year Higher Education Plan of Inner Mongolia (NGYG06030)

\begin{abstract}
Talents are the most important factor of all in the efforts to establish an innovative country. In universities and colleges, the bases for talent cultivation, the turnover of teachers in an explicit or recessive way calls for our urgent attention. This article aims at analyzing the complex causes of college teachers' turnover from the perspective of institutional economics including Limitation of Incentive Theory, Interests Relative Theory and Principal-Agent Theory. Besides, it puts forward some relevant measures to solve the current problem.
\end{abstract}

Keywords: College teachers, Turnover, Institutional economics

In order to establish a well-off society in an all-round way as well as an innovative country, talents, as the most important resources, have drawn greater attention than ever in China. In this current situation, colleges, rich in talents in different fields, are attracting more attention than others, hence a significant source of talent flow. Meanwhile, it should be realized that the lack of high-quality faculty will fail to cultivate talents with creativity and practical capabilities. Therefore, it is quite serious to put importance to the current turnover of teachers, analyze its basic causes and work out some relevant measures.

\section{Definition and Classification of the Turnover of College Teachers}

Here, the turnover of college teachers, different from the natural and healthy talent flow, refers to the vicious one, that is, a lot of talents qualified for their teaching career flow out of school or the education field while the persons who take the place are not sufficient in terms of quality, education background, capacities and so on, resulting in a general decline in faculty $(\mathrm{Li}, 2005)$. The turnover can be divided into explicit one and recessive one according to their different manifestations.

Explicit turnover refers to qualified teachers leave their posts for other places for study or work. According to the survey on the turnover of Chinese college teachers in 2004, as many as $96.6 \%$ of the teachers below 45 years old left their posts; so did $71.1 \%$ with intermediate and associate senior titles and $59.1 \%$ of the teachers with master's degree or above. In addition, $88.9 \%$ of the flowing teachers went abroad or to some developed areas, $78.8 \%$ went to foreign-funded enterprises and state-owned enterprises offering high wages, and also some opened their own business. (Xu, 2004)

Recessive turnover refers to some teachers, regardless of their current teaching responsibility, are devoted to secondary occupation instead of teaching and research activities because of their intention to leave school. According to the survey on six colleges in Central China, among teachers between 45 and 55 years old, $78 \%$ intend to do a part-time job in other schools, $46 \%$ have done or are doing part-time jobs, $28.5 \%$ are determined to do one if it is possible, $44.3 \%$ want to leave but are still worried or have no way to achieve that, only $27.2 \%$ of them don't want to leave their current job (Liu, 2007).

\section{An Analysis on the Turnover of Teachers from the Perspective of Institutional Economics}

There are a variety of explanations for teachers' turnover, including laggard regional economy, poor wages and welfare treatment, imperfect school management, unclear prospect for school development, individuals' high psychological 
stress and so on. However, the conflict between colleges and individuals, between colleges' public-welfare goal and individuals' interests is the main cause for teachers' turnover.

\subsection{An Analysis Based on Public Product Theory}

From the macro perspective, as education belongs to tertiary industry, the education services provided by colleges are para-public products. On one hand, only some people have access to the currently limited education resources; on the other hand, the whole society will benefit from the increase in educated persons. Therefore, a "cost-shared" pattern has been adopted, in which government and individuals should pay for education expenses, that is, students and government pay for the educational products together.

Two features can be found in the transaction of para-public educational products, including the prices set by government and sale by the bale. First, in the transaction among government, students and colleges, students and colleges have nearly lost their rights to state opinions because government set the prices for colleges' services, control their educational expenses, lay down their standard of fees. In this way, colleges have no way to obtain higher price for their better services, hence restricting their own budgeting plans. Second, the education fees obtained by colleges are composed of government's allocation and students' tuition fees. Therefore, with their tuition fees paid, students have actually purchased all the educational services offered by their colleges.

In fact, the services enjoyed by the students are provided by specific teachers, different teachers' services are quite different in quantity and quality. Therefore, they should be paid according to their different services. However, our present transaction system has hindered transaction based on teachers' individual services. In China, teachers' wages is set according to their education background, length of service and qualification instead of their service quality. Failing to show the relations between ability and income, input and rewards, this allocation system will lead to equalitarianism in allocation as well as teachers' recessive turnover such as laziness and low efficiency.

\subsection{An Analysis Based on Limitation of Incentive Theory}

According to Limitation of Incentive Theory designed by Hurwiez, with individuals' goal not completely in agreement with that of their organizations, their interestss often come into conflict. Consequently, every economic man will act based on their own interests. There can be a system arrangement to put individuals' pursuit for their own interests into agreement with their organizations' efforts for maximized value, which is "Limitation of Incentive". It has been shown in modern economic theories and practice that it will solve the conflict between individual and collective interestss and put individuals' behavioral patterns in agreement with maximized collective value to follow "Limitation of Incentive" principle.

In reality, teachers have to face some basic issues such as survival and development, so they are economic men. Although they pursue security, self-esteem, emotion and social status, even unselfish devotion besides economic benefit, basic needs for survival and development as well as maximized individual economic benefit are still important for them.

However, according to China' Higher Education Law, colleges are intended for the national interestss and public interestss instead of profitss to cultivate advanced professional with creativity and practice. That is to say, colleges are not pursuing maximized economic interests as non-profits organizations, which go against teachers' goal for economic interests in market economy. In this situation, it is a rational choice for every economic man to leave school in order to achieve greater interests, resulting in the current explicit turnover of teachers.

\subsection{An Analysis Based on Interests Relative Theory and Principal-Agent Theory}

According to modern Principle-Agent Theory, agents have more knowledge about the information on the production, profits and cost of organizations, that is, "private information", than their owners. Due to the asymmetrical information structure, moral risks or reversed choices may happen before or after market transaction. While according to Interests Relative Theory, a production organization is just a dynamic agreement between human capital and non-human capital, which is adjusted in accordance with their respective value and risks (Zhou, 1996).

From the principle-agent perspective, the administrative staff and teachers from the basic principle-agent relationship, in which the former is the client appointed by government (as well as its agent) while the latter is the agent entrusted with teaching and research tasks. Because teachers have more "private information" and the administrative staff has little access to whether teachers work hard and to what extent they work hard, there is asymmetrical information structure here. Although they can assess teachers' workload in research and teaching roughly, it is not effective due to the difficulty or the high cost to conduct it. Therefore, as long as they have fulfilled the workload allocated to them, teachers will get their wages, with no risk of being fired. In a word, due to the current imperfect monitoring system in colleges, disagreement between teachers' wages and their contribution, their moral risks are inevitable, hence resulting in their insufficient efforts, poor teaching and research quality and a large number of teachers with a part-time job.

From the perspective of interest relatives, colleges, funded by national capital or other organizations, are educational service institutions offering public products for the whole society. Therefore, they can be viewed as dynamic agreements between government or other organizations as the owner of physical capital and teachers as that of human 
capital. If a teacher raises his value by accumulating knowledge and experience, improving his academic and teaching level, he will long for more income as well as better teaching and research conditions provided by the physical capital owner driven by his profits-seeking nature as human capital. On the other hand, the owner of physical capital will ask for more and better services offered by more qualified teachers. In reality, however, college teachers' wages are adjusted in accordance with the national economy and social development instead of teachers' real value although some factors such as title and contribution have been taken into consideration. Consequently, once they can obtain more incremental revenue than current cost, teachers will refuse to sign the contract with their colleges or even violate it to leave school, or stop or cut down the input into teaching and research activities or even take a part-time job.

\section{Institutional Measures against the Turnover of College Teachers}

Trying to fulfill both the public-welfare and the individual goals, colleges' institutional construction should aim at establishing a complete and scientific system to encourage teachers to conduct their teaching and research activities smoothly.

\subsection{Establishing a System of Governments' Long-term Input into Colleges}

Because education services are para-public products, both the society and students benefit from teachers' teaching activities. According to Cost Sharing Theory, government and students are bound to pay for that. But the total payment should be set in accordance with service providers' input and their demands for self-benefit, which is "Limitation of Incentive".

It has happened all over the world that the occupation as a teacher will be appealing and enjoy favorable reputation when teachers' wages lie in the top one third of all professionals with equal qualification, which can be regarded as an objective standard to set teachers' wages (Ma, 1998).

Although it has been laid down in China's Law of Teacher that the average wages of teachers should be no lower than that of civil servants, teachers' wages still seem too low generally, especially in those underdeveloped areas. Therefore, it is critical to establish a system of government's long-term input into colleges to ensure the dynamic regulation of teachers' wages based on market prices, to raise teachers' income referring to the whole society's average wages and those of other professionals and to improve teachers' overall treatment.

\subsection{Establishing a Scientific and Effective Assessment System of College Teachers'Performance}

As the client, colleges are expected to obtain objective knowledge about teachers' efforts and performance in order to ensure efficiency and fairness in wage allocation. With the individual development of teachers in knowledge accumulation, teaching and research abilities, the agreement between the college and every teacher should be put into dynamic adjustment to reflect the changes in human capital's value. Teachers are in bad need of a scientific and effective system to base their wages on their performance. In addition, a new allocation method should be established, in which different wages are given according to different posts and workloads, in order to improve the utilization of resources and avoid recessive turnover of teachers.

\subsection{Reinforcing Students' Dominant Role in Teachers' Performance Assessment}

Currently, the education services monopolized by government as well as a monotonous wage system are still popular in China. In spite of the assessment of teachers conducted in some colleges, the comments given by the administrators have been of dominance, emphasizing government's public-welfare goal while neglecting students' goal for their self-interests.

Actually, the primary target of teachers is students, and carrier of knowledge by teachers is also students. Students have the most direct and objective idea about teachers' performance. Therefore, the establishment of a scientific performance assessment system should intensify leading role of students in performance assessment, and an assessment mechanism with an integration of students, administrators and teachers integrated into a whole should be generated to realize process and result impartiality in income distribution of teachers.

\section{References}

Li, Xingyun. (2005). An Economic Analysis on the Turnover of College Teachers. Education and Economy. (4): p36.

Liu, Rongbin. (2007). On Countermeasures of Local College Teachers' Turnover in Central China. Journal of East China Institute of Technology(Social Science). (1): p41.

Ma, Dan et al. (1998). Problems and Countermeasures of Young Teachers' Turnover in Local Colleges. Higher Education Research in Areas of Communications. (3): p27.

Xu, Shufeng. Chen, Guiying. (2004). Causes and Countermeasures of the Turnover of Chinese College Teachers. Dongyue Tribune. 25: p203.

Zhou, Qiren. (1996). An Enterprise at Market: A Special Contract Between Human Capital and Non-Human Capital. (6): pp. 71-72. 